\title{
Patient engagement or social media marketing?
}

$\mathrm{T}$ he rising use of social media creates an obvious opportunity for certain parties, such as pharmaceutical companies, to engage with the public in new ways.

Advocates of pharmaceutical companies reaching out to potential customers online suggest the industry has been too reluctant to invest heavily in social media strategies, mainly because of a vague regulatory environment. But skeptics of the practice say the pharmaceutical industry is already gung ho about social media, which some companies appear to be using to circumvent restrictions on direct-to-consumer advertising, a practice legal in only the United States and New Zealand.

In a recent report called "Engaging patients through social media," the IMS Institute for Healthcare Informatics states that "the strategies that pharmaceutical companies use to engage with social media could be categorized as low-risk and less innovative than those employed in other industries."

The report notes that use of social media among US adults has grown from $8 \%$ in 2005 to $72 \%$ by 2013 , and that Facebook is the fourth most popular source of health information in the United Kingdom. These numbers are sure to increase, the report suggests, as so-called digital natives - those as comfortable texting and tweeting as they are walking and breathing - grow into adulthood and become more concerned about their health.

Yet the pharmaceutical industry has been slow to embrace social media, claims the IMS Institute, a company based in Danbury, Connecticut. One reason is the lack of guidance from health regulators - in the US, Canada and Europe - about using social media. In the US, for example, the only restriction seems to be on the promotion of off-label uses of drugs. Some companies may be reluctant to invest heavily in a social media strategy for fear of wasting time and resources should strict regulations come into force.

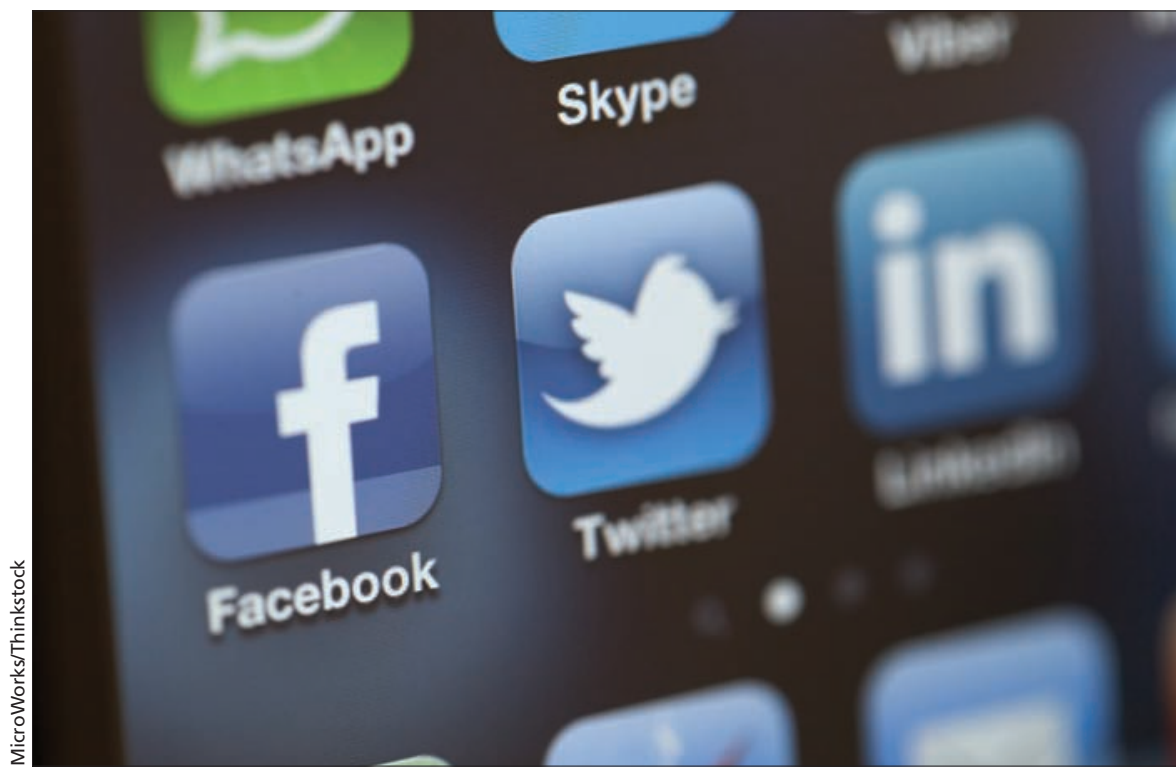

The rising use of social media creates an obvious opportunity for certain parties, such as pharmaceutical companies, to engage with the public in new ways.

Other concerns include how - or whether - to handle claims of adverse events received through social media and how to measure return on investment. New strategies would also be required to respond much more quickly to consumer concerns. A slow response can escalate into a public-relations nightmare with tweets, Tumblr and Facebook comments going viral in hours.

"Users of social media now expect to be able to have a conversation with pharmaceutical companies when they face uncertainties," states the report. "If there is no conversation, or only a standardized answer, it could lead to frustration and be of little overall benefit to both involved parties."

But what does engaging patients really mean in this context? "When you talk about engagement, it is really about direct marketing to the consumer," says Timothy Mackey, an investigator for the San Diego Center for Patient Safety at the University of California San Diego.

In a 2011 paper entitled "Prevalence and global health implications of social media in direct-to-consumer drug advertising," Mackey and colleagues looked at the social media presence of the 10 largest global pharmaceutical corporations. All were active on Facebook, Twitter, sponsored blogs and other social media platforms, and $80 \%$ had YouTube channels. Many individual drugs also had dedicated Facebook pages and Twitter feeds.

This has led to a new form of directto-consumer advertising, developed for interactive social media, which the researchers have dubbed eDTCA 2.0. Though some of these websites state they are intended solely for US residents, the Internet transcends borders. These websites don't appear to restrict access to web users from outside the US, Mackey and colleagues note in their paper.

"The new consumer is one that is global and connected online, a profile that precisely fits the patient/consumer of eDTCA 2.0," the paper states. "Public health policy must take into account this new consumer and the rapidly developing digital environment.'

Some websites set up by drug companies (and medical-device manufacturers) to create communities of potential consumers have scant corporate 
branding and appear to exist primarily to offer free services. These sites, called patient-engagement portals, might offer guidance on how to manage a particular medical problem, such as high blood pressure. They may offer risk assessment tools for sleep apnea or any number of conditions. Some even offer online patient coaches.

"What they are really doing is engaging directly with patients and collecting consumer information, which they may or may not categorize as PHI, or protected health information," says
Mackey. "It's about getting information directly from the consumer, mining data and using that for their own marketing purposes. That's why these websites exist." — Roger Collier, CMAJ

CMAJ 2014. DOI:10.1503/cmaj.109-4739 